\title{
Регионы: антикризисные модели поведения потребителей ${ }^{1}$
}

В.Г. БАСАРЕВА, доктор экономических наук, Институт экономики И организации промышленного Производства СО РАН, Новосибирск. E-mail: vera.basareva@gmail.com

H.H. МИХЕEBA, доктор экономических наук,

Институт народнохозяйственного прогнозирования РАН, Москва.

E-mail: mikheeva nn@mail.ru

В статье сравниваются стратегии поведения населения регионов России в периоды кризиса 2008-2009 гг. и 2014-2015 гг. Показано, что, в отличие от предыдущего кризиса, меры, предпринимаемые Правительством РФ для поддержания спроса населения, менее эффективны, запаздывают по времени, не учитывают региональную специфику адаптации регионов. Выявленные стратегии поведения потребителей в регионах отличаются от оценки их прогнозируемого поведения для страны в целом, что позволяет использовать предлагаемый метод для уточнения национальных прогнозов.

Ключевые слова: агрегированный потребитель, динамика реальных доходов, потребительский спрос, антикризисная программа, прогнозы

\section{Опыт кризиса 2008-2009 гг.}

В кризисном 2009 г. рост безработицы и снижение реальной заработной платы оказали существенное давление на реальные доходы населения, однако рост реального размера пенсий $(10,7 \%$ к уровню 2008 г.) и повышение заработной платы бюджетников позволили избежать падения реальных располагаемых доходов населения - в целом по стране они выросли на 1,8\%. Положительная динамика очень неравномерна по территориям: в 2008 г. реальные доходы населения снизились в Центральном и Северо-Западном федеральных округах, в 2009 г. - в Уральском и Сибирском.

Рост реальных доходов населения не привел к увеличению потребительских расходов: оборот розничной торговли сократился на $5,1 \%$, платных услуг населению - на 2,5\%. Падение индексов этих показателей отмечалось во всех федеральных 
округах, кроме Северо-Кавказского и Дальневосточного. Называют две причины такого поведения потребителей - значительные выплаты по ранее взятым потребительским и инвестиционным кредитам (в 2007-2008 гг. - бум потребительского кредитования) и ускоренный рост сбережений (в 2009 г. - на 27\% в номинальном выражении) [1].

Характерная в целом для России стратегия сбережения, когда рост реальных доходов сопровождался сокращением объемов розничного товарооборота и платных услуг в сопоставимых ценах, существенно дифференцировалась по регионам. Анализ показал, что прослеживалось семь вариантов стратегий поведения агрегированного потребителя². Каждая из них была сформирована сочетанием динамики трех показателей (за 2009 г. по отношению к предыдущему году): изменение реальных доходов населения; рост (снижение) оборота розничной торговли и объема платных услуг в сопоставимых ценах.

Стратегия 1. «Стратегия сбережения». Реальные доходы населения росли в 2009 г. по сравнению с 2008 г., но фиксировалось сокращение объемов платных услуг и розничного товарооборота в сопоставимых ценах. Наряду с Россией в целом такая стратегия отмечалась еще в 12 субъектах РФ: Москве, Санкт-Петербурге, Брянской, Волгоградской, Калужской, Новосибирской, Пензенской, Самарской, Тверской и Тульской областях, республиках Карачаево-Черкесия и Удмуртия.

В этих регионах проживало $23,3 \%$ населения России, работало $24,8 \%$ от общей численности занятых в экономике. Большинство из них - регионы миграционного притяжения и только три из 12 имели отрицательное миграционное сальдо. Реальная заработная плата падала в 2009 г. во всех регионах этой группы, а реальные доходы росли за счет пенсий, доходов от предпринимательской деятельности и собственности, других доходов, в том числе от продажи валюты и пр. Группа весьма разнородна, и это позволяет предположить, что в разных регионах действовали разные факторы.

2 В расчеты не включена Чеченская Республика, по которой нет данных. Регионы, в которыххотя бы один из указанных показателей в 2009 г. не изменился, не включались в группировку, поэтому суммарное по группам число регионов не равно 82.
Падение реальных доходов в столичных агломерациях произошло еще в 2008 г., для Москвы и Санкт-Петербурга влияние мирового кризиса оказалось наиболее сильным, доходы сократились даже на фоне положительной динамики реальной заработной платы. Снижение реальной заработной платы, объемов розничного товарооборота и платных услуг населению наблюдалось в 2009 г., когда индексы реальных доходов на фоне спада 2008 г. оказались положительными.

В данную группу попали также регионы с более высокой, чем в среднем по России, долей сельского населения (Брянская, Волгоградская, Пензенская и Тверская области, республики Карачаево-Черкесия и Удмуртия). Для таких регионов в большинстве случаев удельный вес населения с доходами ниже прожиточного минимума превышает среднероссийский, а рост реальных доходов можно объяснить наличием подворья, которое страховало домохозяйства.

Вместе со столицей в эту группу попали соседние регионы: Калужская, Тверская, Тульская области, жители которых могли выезжать на заработки в Москву. Оказались здесь и регионы, получавшие из федерального бюджета трансферты на поддержку занятости - Удмуртская Республика, Волгоградская и Самарская области.

Стратегия 2. «Бегство от наличных денег». Малочисленная по своему составу группа, в которой реальные доходы населения падали, но фиксировался рост объема платных услуг населению и розничного товарооборота в сопоставимых ценах. Такая ситуация отмечалась в пяти субъектах Российской Федерации: Белгородской и Сахалинской областях, республиках Кабардино-Балкария и Северная Осетия-Алания, Чукотском АО. В этих регионах проживало $2,6 \%$ населения России, было занято в экономике $2,5 \%$ от общего числа.

В дальневосточных регионах с высоким уровнем номинальных доходов доля потребительских расходов в располагаемых доходах существенно ниже средней по стране, поскольку значительная часть доходов реализуется за пределами регионов, в северокавказских регионах вероятна высокая доля теневых доходов. В обоих случаях падение реальных доходов не отразилось на покупательском спросе. Для всех четырех регионов характерна отрицательная миграция. Попадание в данную группу 
Белгородской области может быть обусловлено статистическим эффектом: доходы в области упали всего лишь на $0,2 \%$, розничный товарооборот вырос на $0,8 \%$.

Прирост финансовых активов у регионов этой группы был в среднем выше среднероссийского - $17 \%$.

Стратегия 3. «У нас кризиса нет». В 12 регионах фиксировался рост реальных доходов населения, объемов платных услуг населению и розничного товарооборота в сопоставимых ценах. Это Новгородская область, Камчатский, Ставропольский и Хабаровский края, Еврейская и Ненецкий АО, республики Адыгея, Дагестан, Ингушетия, Марий Эл, Бурятия и Саха (Якутия). В них проживало 8,1\% населения России и работало 7,3\% всех занятых. Благополучие этих регионов связано в основном с антикризисной федеральной помощью (Дагестан, Ингушетия, Еврейская АО, Камчатский край), а также реализацией федеральных целевых программ на Северном Кавказе и Дальнем Востоке.

Стратегия 4. «Живу по средствам». Реальные доходы населения падали по сравнению с 2008 г., фиксировалось снижение объема платных услуг населению и розничного товарооборота в сопоставимых ценах. Такая ситуация отмечалась в 20 субъектах: Вологодской, Иркутской, Кемеровской, Кировской, Костромской, Курской, Московской, Мурманской, Омской, Ростовской, Рязанской, Смоленской, Томской, Ульяновской и Челябинской областях, Алтайском и Красноярском краях, республиках Карелия, Коми и Чувашия.

Здесь проживало 27,8\% населения России и было занято $28 \%$ от общей численности. В группу вошли индустриальные регионы Северо-Запада, Центра, Приволжья, Сибири, в которых отмечался заметный спад промышленного производства. Для них характерна высокая доля безработных в экономически активном населении. Фиксировался отток населения из большинства регионов этой группы.

Стратегия 5. «Доходы падают, но услуги оплачивать надо». Реальные доходы населения упали, фиксировались рост объема платных услуг населению и падение объема розничного товарооборота. Такая ситуация сложилась в 13 субъектах: Амурской, Воронежской, Курганской, Нижегородской, Орловской, Псковской, Тамбовской, Тюменской и Ярославской областях, Пермском крае, Ханты-Мансийском и Ямало-Ненецком АО, Республике Алтай.
В этих регионах проживало 16\% населения России и трудилось 13,8\% занятых. В группу попали нефтегазодобывающие регионы (ХМАО, ЯНАО, Тюменская область), тяжело переживавшие кризис, но тем не менее сохранившие лидерство по уровню номинальных и реальных доходов, а также территории, получившие поддержку центра из-за сложностей на рынке труда (Орловская и Ярославская области). Большинство из перечисленных регионов лидируют в России по объемам транспортных и коммунальных услуг на душу населения. Для них также характерен высокий процент обязательных платежей в используемых денежных доходах, а в восьми регионах он выше, чем в среднем по России.

Стратегия 6. «Доходы выросли, оплачу услуги». При росте реальных доходов населения фиксировались рост объема платных услуг населению и падение объема розничного товарооборота Такая ситуация сложилась в 12 субъектах: Архангельской, Астраханской, Владимирской, Магаданской, Оренбургской, Саратовской и Свердловской областях, Забайкальском и Приморском краях, республиках Мордовия, Татарстан и Тыва.

В этих регионах проживало 17,3\% населения России и трудилось 14,4\% всех занятых. Потребительский спрос поддерживался за счет сферы услуг. Реальные доходы населения росли, в том числе за счет инъекций федерального центра (Забайкальский и Приморский края, Республика Тыва).

Стратегия 7. «Увеличились доходы - куплю товары». Реальные доходы населения увеличивались по сравнению с 2008 г., фиксировались падение объема платных услуг населению и рост объема розничного товарооборота в сопоставимых ценах. Такая ситуация сложилась только в трех субъектах Российской Федерации: Калининградской области, Краснодарском крае и Республике Калмыкия.

В этих регионах проживало 4,5\% населения России и трудилось $4,2 \%$ всех занятых. Все три региона имели федеральную поддержку по разным направлениям. Ввиду малочисленности группы другие характерные особенности выделить было затруднительно.

Отметим, что регионы выбирали одинаковую стратегию под воздействием различных факторов. Структура потребительских предпочтений во многом была создана усилиями центра, 
который предоставил антикризисную масштабную помощь в виде дотаций на выравнивание бюджетной обеспеченности и поддержку сбалансированности бюджетов, трансферты на поддержку занятости. Еще одна отличительная черта кризисных явлений 2009 г.: для населения предпочтительнее было сохранить достигнутый уровень услуг даже при сокращении доходов. Это было в значительной мере вынужденно, поскольку непросто сократить расходы на коммунальные услуги и услуги транспорта, которые доминируют в структуре платных услуг населению, и тем не менее в 46 регионах, где проживало почти 42\% населения, потребительский спрос на рынке услуг поддерживался.

Общей тенденцией изменения стратегии поведения потребителей после кризиса для большинства регионов был абсолютный и относительный рост потребительских расходов. Номинальные доходы в 2010 г. в среднем по стране выросли примерно в 1,5 раза, потребительские расходы, которые в 2007 г. достигали 10 тыс. руб. на душу населения лишь в самых богатых регионах, в 2010 г. приблизились к этому уровню почти повсеместно, исключая самые бедные регионы. Перераспределение ресурсов в пользу потребительских расходов происходило за счет снижения сбережений (приобретения финансовых активов) и уменьшения наличных денег у населения. Сбережения в большей мере снижались в регионах с высоким уровнем доходов, в которых в 2009 г. происходило наиболее сильное сокращение реальных доходов.

В кризис снизились межрегиональные перетоки потребительских расходов. Отрицательный знак показателя изменения сумм денег у населения в большинстве случаев означает приток денег из других регионов. В 2006 г. такой знак имели Москва, Московская область, Санкт-Петербург, Краснодарский, Приморский и Ставропольский края, Амурская и Новосибирская области регионы, в которых значительная часть потребительского спроса формировалась за счет расходов приезжих из других регионов. В 2010 г. чистый ввоз денег имел место только в Москве и СанктПетербурге, Краснодарском и Ставропольском краях.

Фактором быстрого восстановления потребительского спроса стали и изменения в структуре доходов населения. Несмотря на то, что заработная плата продолжала оставаться основным источником доходов, увеличилась доля социальных трансфертов.
Так называемые «другие» источники денежных доходов в отдельных регионах могли приближаться к уровню доходов по оплате труда и значительно превосходить социальные выплаты. В ряде регионов доля оплаты труда в структуре источников денежных доходов была сравнима или даже меньше «других» источников (Брянская, Липецкая, Ростовская и Челябинская области, республики Башкортостан, Ингушетия и Татарстан).

Появление источников дохода, не связанных с непосредственной занятостью или обусловленных теневой занятостью, в послекризисный период стало играть большую роль в формировании доходов. Нельзя исключить, что такие источники доходов связаны с банковским сектором (валютные операции с населением, активизация потребительского кредитования) и теневой занятостью, которая по большей части формировалась малым предпринимательством.

\section{5+}

Какие же тенденции сложились в России в 2015 г., когда реальные доходы населения удержались от падения или чуть превысили значения предыдущего года только в шести субъектах Федерации? Представим стратегии регионов Р $\Phi^{3}$ на основе анализа тех же трех показателей в сопоставимых ценах 2015 г. по отношению к 2014 г. [2,3].

Стратегия 1. «Стратегия сбережения». В 2015 г. ее выбрали только три (вместо 12 в 2009 г.) субъекта Федерации - Республика Удмуртия, Пермский и Хабаровский края.

Стратегия 2. «Бегство от наличных денег». Данная ситуация сложилась в четырех субъектах Федерации: республиках Бурятия, Ингушетия и Чечня, Чукотском АО.

Стратегия 3. «У нас кризиса нет». Ситуация отмечена в единственном регионе - Приморском крае.

Стратегия 4. «Живу по средствам». Наиболее распространенная ситуация, которая сложилась в 53 субъектах Федерации (в 2009 г. - 20). В регионах данной группы проживает $65 \%$ населения России.

3 В целях обеспечения статистической сопоставимости - без учета данных по Республике Крым и г. Севастополь. 
Стратегия 5. «Доходы падают, но услуги оплачивать надо». Отмечена в 19 субъектах Федерации: Белгородской, Вологодской, Калининградской, Липецкой, Псковской, Ростовской, Сахалинской, Свердловской, Тверской и Томской областях, Алтайском, Камчатском и Краснодарском краях, республиках Алтай, Кабардино-Балкария, Калмыкия, Карелия, Северная Осетия-Алания и Татарстан. В 2009 г. таких регионов было 13.

Стратегия 6. «Доходы выросли, оплачу услуги». Использовали два субъекта Федерации: Воронежская и Ленинградская области.

Стратегия 7. «Увеличились доходы - куплю товары». Не отмечена ни в одном из регионов.

В кризис 2008-2009 гг. ситуация характеризовалась значительным региональным разнообразием, что позволило выделить семь стратегий потребительского поведения. В 2015 г. падение реальных доходов было практически повсеместным, и подавляющее большинство регионов выбрали одну из двух стратегий: «Живу по средствам» или «Доходы падают, но услуги оплачивать надо». Небольшие колебания в предпочтениях, которые выбрали 2-3 региона, скорее подчеркивают две главные тенденции.

Первая - население в 2015 г. в первую очередь сократило потребление товаров, спрос не поддерживается практически повсеместно, динамика розничного товарооборота оказалась положительной лишь в пяти субъектах РФ. Вторая - в 25\% регионов при падении доходов население предпринимает попытки сохранить привычную структуру услуг, львиную долю которых составляют неэластичные коммунальные и услуги транспорта.

Тенденция согласия на сокращение потребления достаточно тревожная. В прошлый кризис 1/3 населения выбирало такую усредненную стратегию, а в новый кризис - уже большинство. Такую оценку подтверждают и другие эксперты [4].

Реальные доходы населения в 2015 г. в восьми субъектах Федерации снизились более чем на $10 \%$, в Республике Ингушетия - на 21\%, Адыгее - на 11\%, Самарской области - на 10,5\%, Ульяновской - на 10\%. На уровне федеральных округов падение доходов было не столь существенным - не выше 5\%, сокращение оборота розничной торговли было значительнее. Федеральные округа в 2015 г. компенсировали падение доходов за счет сокращения потребления товаров и в меньшей степени изменяли привычную структуру услуг (рис. 1)

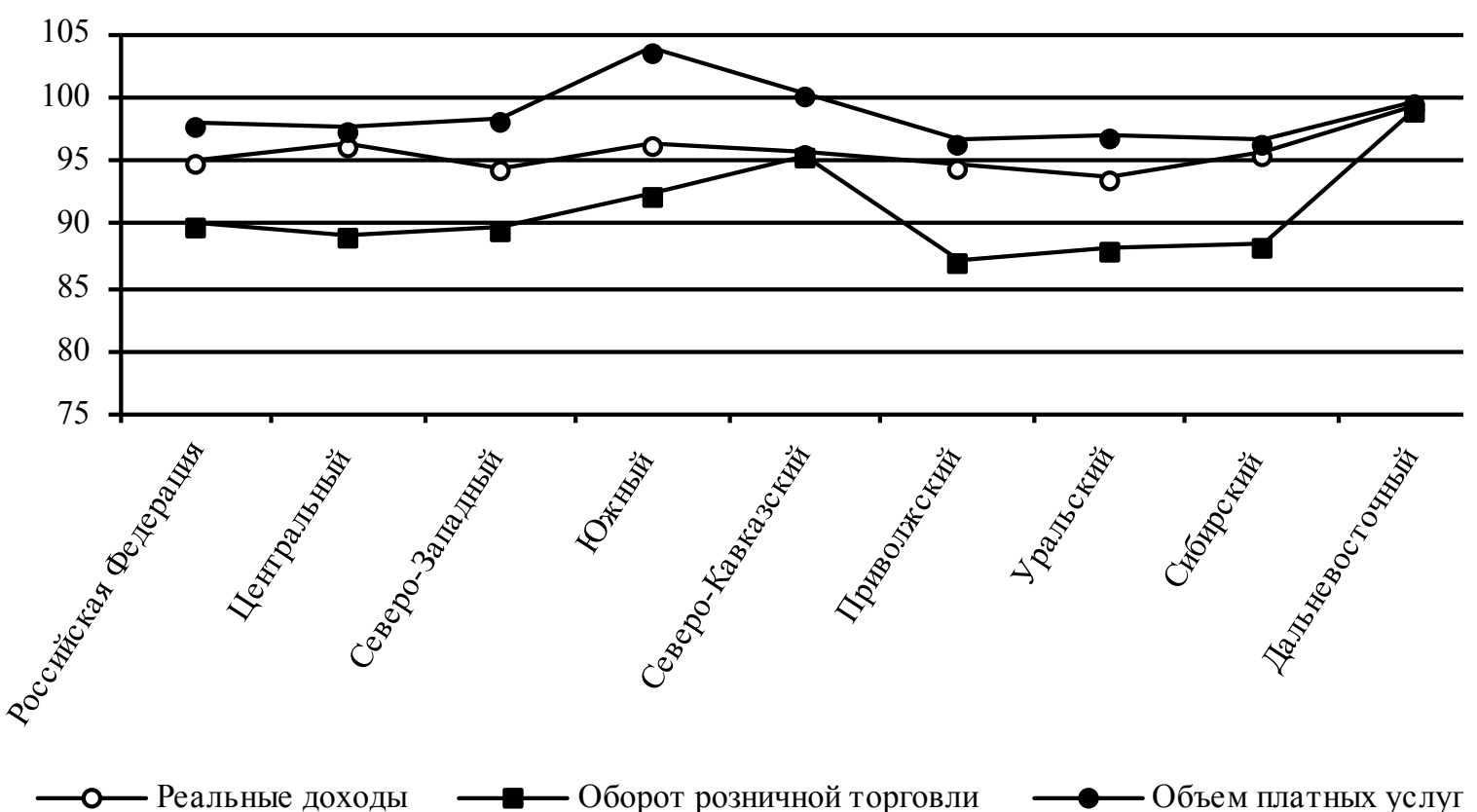

—— Реальные доходы

Оборот розничной торговли

Объем платных услуг

Источник: [3]

Рис. 1. Динамика реальных доходов населения и потребительского спроса в федеральных округах в 2015 г., \% к 2014 г.

Как скоро наступит перелом в динамике доходов? Вопрос времени. Нельзя не согласиться с Н. Зубаревич, которая предупреждает: «Когда привыкаешь, перестаешь сопротивляться и прилаживаешься каждый раз к тому, что есть, - это заканчивается деградацией. Вот в чем риски этого кризиса. Привыкание, адаптация к худшему и деградация - это самое в нем опасное» [5].

Если в прошлый кризис положительные тенденции наметились уже в 2010 г., то в 2016 г. перелом вряд ли получится. По крайней мере, Минэкономразвития таких изменений в среднесрочный прогноз не закладывает: «В 2016 г. за счет отмены индексации заработной платы бюджетников и более низкой, чем в сценарных условиях, индексации пенсий реальные располагаемые доходы населения останутся в области отрицательных значений $(-0,7 \%$ к уровню 2015 г.). В 2017-2018 гг. ожидается постепенное ускорение роста реальных располагаемых доходов до 1,5-1,9\%» [6].

Первые месяцы 2016 г. подтверждают прогнозы. По предварительным данным Росстата, реальные располагаемые денежные 
доходы (суммарные по регионам) в январе 2016 г. по сравнению с соответствующим периодом предыдущего года упали на 5,5\%, в январе-марте 2016 г. - на 4,1\%. В региональном разрезе за январь-март 2016 г. показатель реальных денежных доходов снизился в 67 субъектах РФ. Продолжает сокращаться потребление. Оборот розничной торговли за январь-апрель 2016 г. и объем платных услуг населению упали в 62 регионах.

По данным Минэкономразвития [7], до конца года население продолжит активно создавать сбережения с целью защитить свои доходы от высокой инфляции, формируя «резерв» на случай возможного ухудшения экономической ситуации. По мере стабилизации и восстановления потребительской уверенности, поддерживаемой ростом доходов, склонность населения к сбережениям начнет снижаться. Это характерно для страны в целом. Но есть и пространственные различия.

Один из видов сбережений населения - банковские вклады. Центробанк аккумулирует и представляет на своем сайте сведения о средствах физических лиц в рублях и иностранной валюте по 30 крупнейшим банкам, в том числе в разрезе федеральных округов и регионов [8]. В 2015 г. (сопоставлялись данные ЦБ на 01.01.2016 г. и 01.01.2015 г.) средства на счетах и в рублях, и в валюте увеличивались во всех федеральных округах (рис. 2).

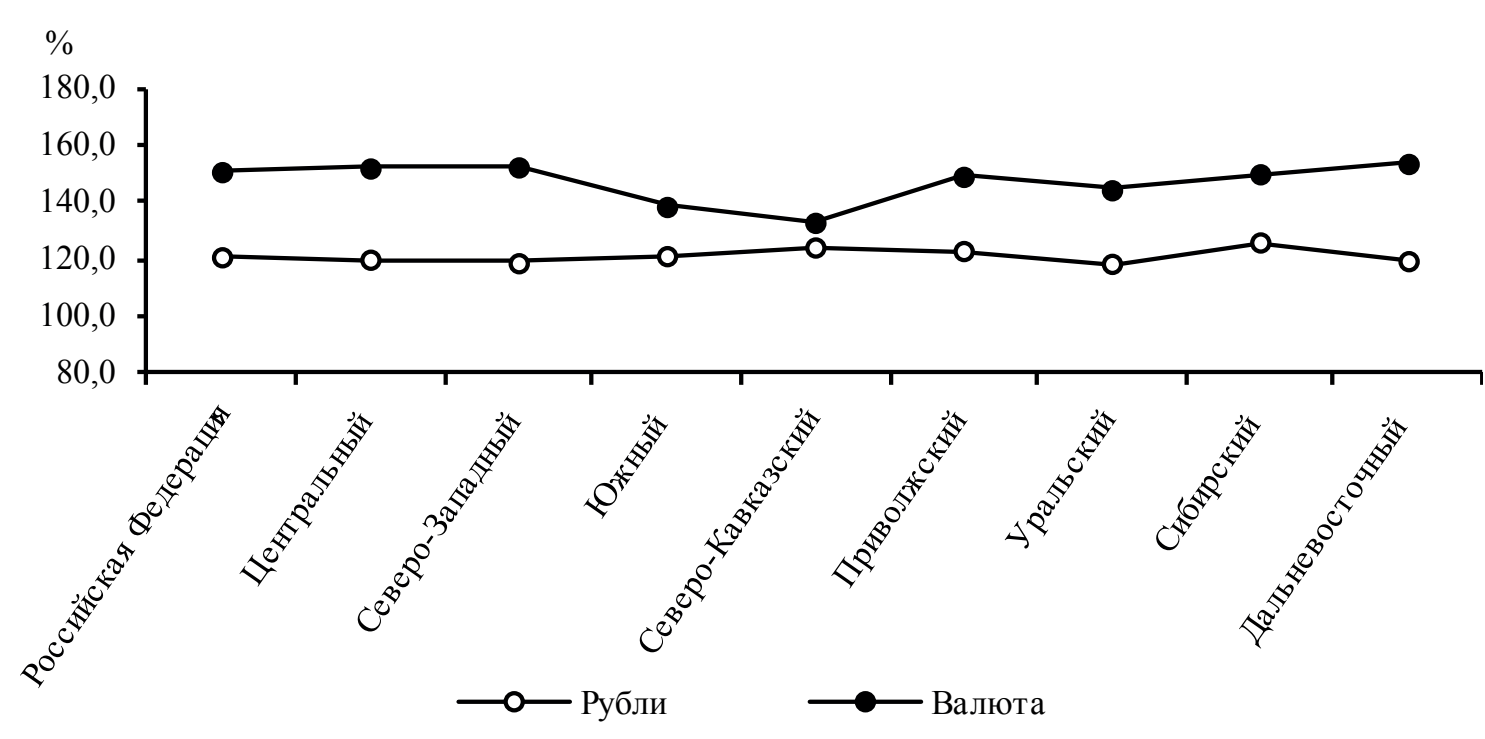

Источник рис. 2-3: рассчитано по данным ЦБ России. URL: www.cbr.ru

Рис. 2. Динамика средств на банковских депозитах физических лиц в рублях и иностранной валюте по 30 крупнейшим банкам за 2015 г., \%
Но уже в первые месяцы 2016 г. в некоторых федеральных округах население, вероятнее всего, начало использовать эти сбережения. На рисунке 3 представлено сопоставление данных за 01.02.2016 г. и 01.01.2016 г. по федеральным округам. Средства на депозитах в рублях уменьшились в январе 2016 г. во всех округах. При этом средства на депозитах в валюте увеличились в Центральном, Северо-Западном, Северо-Кавказском, Уральском федеральном округах, а снизились - в Южном, Приволжском, Сибирском и Дальневосточном округах. В этих округах сбережения на депозитах сокращались, но потребительский спрос не увеличивался!

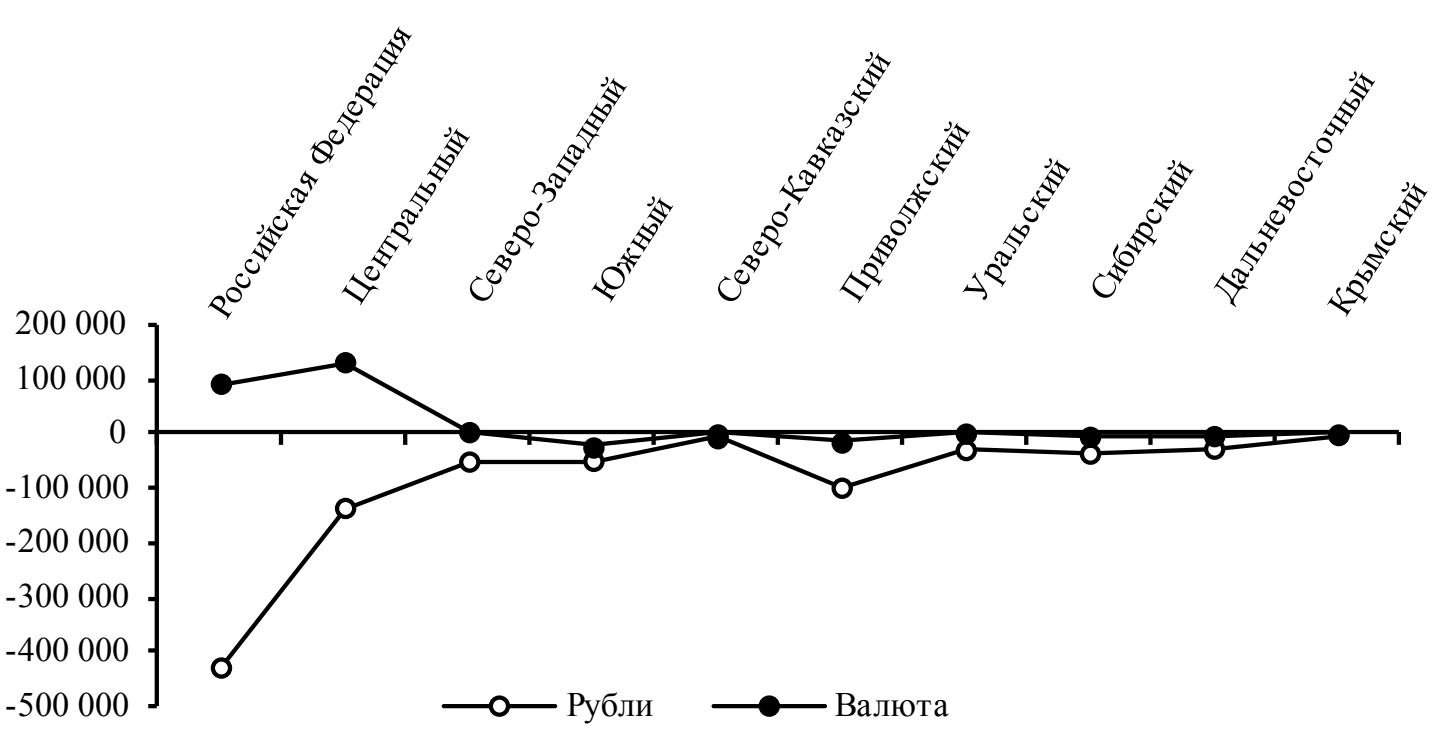

Рис. 3. Прирост (снижение) средств

на банковских депозитах физических лиц

в рублях и иностранной валюте по 30 крупнейшим банкам за январь 2016 г., млн руб.

Возможное объяснение этой ситуации - перекладывание рублевых сбережений в валютные, другое - валюту проедали или оплачивали услуги.

В кризис 2008-2009 гг. антикризисная помощь из федерального бюджета, трансферты на поддержку занятости смягчали ситуацию. Например, на повышение максимального размера пособий по безработице с 3124 руб. до 4900 руб. в 2009 г. планировалось выделить 33,9 млрд руб., софинансирование региональных программ по занятости - 43,7 млрд руб. [9].

В «Плане действий Правительства, направленных на обеспечение стабильного социально-экономического развития Российской 
Федерации в 2016 г.», принятом 1 марта 2016 г., субсидии из федерального бюджета бюджетам субъектов РФ на реализацию дополнительных мероприятий в сфере занятости населения составляют 3 млрд руб., бюджетные ассигнования на предоставление субвенций бюджетам субъектов РФ на предоставление социальных выплат безработным гражданам - 5,5 млрд руб. [10]. Такие микроинъекции вряд ли изменят ситуацию.

В плане антикризисных мер в 2009 г. правительством предусматривалось увеличение расходов федерального бюджета на государственную поддержку субъектов малого предпринимательства до 10,5 млрд руб., т. е. в дополнение к ранее запланированным средствам выделялось 6,2 млрд руб. В 2016 г. подобные меры не предусмотрены. В то же время очевидно, что снижение платежеспособного спроса населения - серьезная угроза для малого предпринимательства. Половина оборота розничной торговли приходится на него, и при спаде спроса малый бизнес ответит сокращением рабочих мест! Даже в Москве занятость в сфере малого предпринимательства в 2015 г. сократилась на 2,6\% [11].

\section{$\star \star \star$}

Основная задача антикризисной политики - трансформировать имеющиеся предпосылки в действующие факторы роста, среди которых стимулирование потребительского спроса занимает центральное место. Он сам по себе может вернуть российскую экономику к положительным темпам роста $[12,13]$ Меры, принимаемые Правительством РФ, явно недостаточны и запаздывают по времени

Не учитывается специфика адаптации регионов к кризисным явлениям. Представляется, что региональные особенности формирования потребительского спроса и доходов населения позволили бы более точно учитывать существенные изменения при прогнозировании национальных показателей, в том числе намечаемые стратегические меры по модернизации экономики и социальной сферы [14].

Действия Правительства ориентированы на поддержку отраслей. Недостаточны меры, способствующие восстановлению положительной динамики потребительского спроса в разрезе субъектов Федерации, которые могли бы ускорить нормализацию макроэкономической ситуации, обеспечить переход на восстановление экономического роста в краткосрочном периоде.

\section{Литература}

1. Итоги 2009 г. и прогноз на долгосрочную перспективу. ЦМАКП, 2010. URL: http://www.forecast.ru/_ARCHIVE/MONITORING/2010/Mon2009.pdf 2. Социально-экономическое положение России, 2015 г. - М., РОССТАТ 9.02.2016, № ИМ-04-1/30-СД.

3. Об итогах социально-экономического развития Российской Федерации в 2015 г. Минэкономразвития. - М., февраль 2016. - C. 109. URL: http://economy.gov.ru/minec/about/structure/depMacro/2016090201

4. Суслов Н.И. Новый российский кризис: снижение потребления на фоне социальной апатии // ЭКО. - 2016. - № 4. - С. 44-55.

5. Зубаревич Н.: «В ближайшие пять-семь лет будет социальная деградация». URL: http://so-I.ru/news/show/tekst $v$ blizhayshie pyat_sem let_budet_socialnaya

6. Прогноз социально-экономического развития Российской Федерации на 2016 год и на плановый период 2017 и 2018 годов. Редакция октябрь 2015. URL: http://economy.gov.ru/minec/about/structure/ depmacro/20151026

7. О текущей ситуации в экономике Российской Федерации в январефеврале 2016 г., Минэкономразвития. - М., март 2016. URL: http://economy.gov.ru/minec/activity/sections/macro/monitoring/monitoring2016month2 8. Центробанк РФ: Сведения о средствах организаций, банковских 8. Центробанк РФ: Сведения о средствах организаций, банковских депозитах (вкладах) и других привлеченных средствах юридических и физических лиц в рублях, иностранной вал

9. Программа антикризисных мер Правительства Российской Федерации на 2009 год. URL: http://rg.ru/2009/03/20/programma-antikrisis-dok. html

10. План действий Правительства РФ, направленных на обеспечение стабильного социально-экономического развития РФ в 2016 г. URL: http:// government.ru/govworks/476/events

11. Малый бизнес Москвы впервые за четыре года начал сокращать персонал. URL: http://www.rbc.ru/ins/own_business/25/03/2016/56f42a5 79a79475dadf1cdb2?from=main

12. Ивантер В.В. Стратегия перехода к экономическому росту // Проблемы прогнозирования. - 2016. - № 1. - С. 3-7.

13. Прогноз индикаторов экономики РФ: 2015-2018 гг. (инерционный сценарий). Квартальный прогноз, ИНП РАН, Вып. № 33. - С. 3. URL: http:// www.rg.ru/pril/article/117/79/87/Prognoz_INP_RAN.pdf

14. Михеева Н. Н., Басарева В. Г. Особенности территориальной структуры формирования потребительского спроса и доходов населения. Проблемы управления социально-экономическим развитием регионов Сибири: сб. науч. тр. / Под ред. А. С. Новосёлова; ИЭОПП СО РАН. - Новосибирск, 2013. - С. 208-221. 